TITLE:

\title{
Development and fundamental study on a superconducting induction/synchronous motor incorporated with MgB2 cage windings
}

\section{AUTHOR(S):}

Nakamura, T; Yamada, Y; Nishio, H; Kajikawa, K; Sugano, M; Amemiya, N; Wakuda, T; Takahashi, M; Okada, M

\section{CITATION:}

Nakamura, T ...[et al]. Development and fundamental study on a superconducting induction/synchronous motor incorporated with MgB2 cage windings. Superconductor Science and Technology 2012, 25(1): 014004.

\section{ISSUE DATE:}

2012-01-01

URL:

http://hdl.handle.net/2433/152379

\section{RIGHT:}

(c) IOP Publishing 2012; This is not the published version. Please cite only the published version.; この論文は出版社版でありません。引用の 際には出版社版をご確認ご利用ください。 


\title{
Development and fundamental study on superconducting induction/synchronous motor incorporated with $\mathrm{MgB}_{2}$ cage windings
}

\author{
T. Nakamura ${ }^{1}$, Y. Yamada ${ }^{1}$, H. Nishio ${ }^{1}$, K. Kajikawa ${ }^{2}$, M. Sugano ${ }^{1}$, N. Amemiya ${ }^{1}$, T. Wakuda ${ }^{3}$, \\ M. Takahashi ${ }^{3}$ and M. Okada ${ }^{4}$ \\ 1. Department of Electrical Engineering, Graduate School of Engineering, Kyoto University, \\ 1 Kyoto-Daigaku-Katsura, Nishikyo-Ku, Kyoto 615-8510, Japan \\ 2. Research Institute of Superconductor Science and Systems, Kyushu University, 744 \\ Motooka, Nishi-ku, Fukuoka 819-0395, Japan \\ 3. Hitachi Research Laboratory, Hitachi, Ltd., 7-1-1 Omika, Hitachi 319-1292, Japan \\ 4. Tsukuba Innovation Arena Promotion Division, National Institute of Advanced Industrial \\ Science and Technology (AIST), 1-1 Umezono, Tsukuba 305-8568, Japan \\ E-mail: tk_naka@kuee.kyoto-u.ac.jp (Taketsune Nakamura, Kyoto University)
}

\begin{abstract}
In this paper, fundamental study on rotating characteristics of the induction/synchronous motor by use of superconducting $\mathrm{MgB}_{2}$ cage windings is carried out based on the analysis and the experiment. Current transport property of the produced monofilamentary $\mathrm{MgB}_{2}$ wires are firstly characterized, and then utilized for the determination of the current carrying capacity of the rotor bars. And then, the motor model is designed and fabricated with the aid of the conventional (copper) stator windings. We successfully observe the synchronous rotation of the fabricated motor at the rotation speed range from $300 \mathrm{rpm}$ to $1800 \mathrm{rpm}$. We can also realize almost constant torque vs. speed curve, and this characteristic is explained from the steep take-off of the electric field vs. current density curve, based on the nonlinear electrical equivalent circuit. These results are promising for the practical application of the high efficiency motor for the liquid hydrogen circulation pump.
\end{abstract}

\section{Introduction}

We have been developing the high efficiency superconducting motor for the circulation pump of the liquefied fuel [1]. Especially, hydrogen fuel is regarded as one of the next generation clean energy sources, and its liquid state is more efficient for the circulation and/or transportation of such fuel, compared to other state. It is widely known that the atmospheric boiling point of the hydrogen is $20 \mathrm{~K}$, and is suitable for the 
coolant of the superconducting machines. In other words, it is not necessary to worry about the cooling problem of the superconducting motor, when we consider such motor incorporated to the circulation pump of such liquid fuel.

With respect to the superconducting circulation pump, Dew-Hughes and his co-workers have got the UK patent for the liquid fuel circulation pump by the use of the HTS bulk motor [2], and have reported the fundamental research results [3]. Komori's group has also developed the HTS bulk motor for the liquid cryogen circulation pump [4].

On the other hand, basic structure of our liquid fuel circulation pump motor is so-called squirrel-cage type induction machine, which have widely been utilized as the conventional (normal conducting) ones because of its simple structure, easy maintenance, etc. One of the project members has already shown that high performance motors can be realized by replacing the secondary windings with the superconducting (zero resistance) wires, i.e., coexistence of slip and synchronous rotation modes, high efficiency thanks to the steady state synchronous operation, high torque density, robustness against the overload (avoidance of the step-out), etc [5-9]. This motor is called superconducting induction/synchronous machine. Further, we have been challenging the fabrication of fully superconducting motor, i.e., both the stator and rotor windings consist of $\mathrm{MgB}_{2}$ wires. One of the most important merits for use of the $\mathrm{MgB}_{2}$ wires is its potential low cost production compared to any oxide high temperature superconductor (HTS) materials. Although the critical temperature of the $\mathrm{MgB}_{2}$ wires is around $39 \mathrm{~K}$, it is enough to be used for the liquid hydrogen applications (20 K). Furthermore, our motor utilizes the iron core in order to make strong magnetic circuit, and then the $\mathrm{MgB}_{2}$ wires are installed in the slots of such cores. That is, much magnetic fluxes go through the iron core not the wires themselves, and we don't need to consider the magnetic field dependency of the critical current density of the $\mathrm{MgB}_{2}$ wires. Namely, it will be possible to realize low cost and high performance motor for the liquid fuel circulation pump.

In this paper, the superconducting induction/synchronous motor with the use of the monofilamentary $\mathrm{MgB}_{2}$ rotor windings is designed and fabricated for the target operation temperature range from $4.2 \mathrm{~K}$ to $20 \mathrm{~K}$. And then, the fundamental characteristics of the fabricated motor are investigated based on the experiment and the analysis. Our final goal is the realization of the fully-superconducting motor, i.e., both of stator and rotor windings are made of $\mathrm{MgB}_{2}$ wires, and the characteristics of such wires subjected to AC current is energetically studied for the design of the low loss stator windings $[10,11]$. This paper, however, reports about the motor in which only 
rotor windings are fabricated by using $\mathrm{MgB}_{2}$ wires as a first step. Detailed performance of such motor is reported and discussed.

\section{Fabrication of $\mathrm{MgB}_{2}$ cage windings}

\subsection{Characterization of $\mathrm{MgB}_{2}$ wire}

Mono-core $\mathrm{MgB}_{2}$ round wires (0.8 $\mathrm{mm}$ in diameter) are produced by means of in-situ method at HITACHI Research Laboratory, Japan. Figure 1 shows the optical micrograph of the cross section of the produced wire. As can be seen, the Nb layer is introduced as the barrier material, and the $\mathrm{Cu}$ is used for the sheath.

Firstly, we characterize the current transport property of the produced wire by means of the 4-probe method. Figure 2 shows a photograph of the sample holder. Such holder is installed in the metal cryostat, and then the sample is cooled by means of the gas He flow. Figure 3 shows the experimental results of (a) critical current and (b) n-value as a function of the temperature. It should be noted that all results are obtained at the steady state. That is, we carry out the measurement after the reach of stable temperature. From this figure, so-called irreversibility temperature of the wire is about $36 \mathrm{~K}$, i.e., critical current is zero at this temperature. Unfortunately, the measurement cannot be performed when the temperature is below $26 \mathrm{~K}$ because of the heating problem of the sample holder. Therefore, we try to approximate the lower temperature characteristics with the aid of the Kramer's expression [12] as follows.

$$
I_{a}=560.1 \mathrm{~A} \cdot\left\{1-\left(\frac{T}{36 \mathrm{~K}}\right)^{2}\right\}^{1.99}
$$

Solid curve in figure (a) is the fitted result, and we can find that such expression agrees well with the experimental results. Then, based on such expression, we estimate the current transport properties at lower temperatures. That is, critical current and n-value are, respectively, $335.7 \mathrm{~A}$ and 190 at $20 \mathrm{~K}$ (atmospheric boiling point of liquid hydrogen). Further, we carry out the rotation test of the fabricated motor in liquid helium ( $4 \mathrm{~K}$ ) as a first step in this paper, and the critical current at such temperature is estimated to be 550. 5 A by means of equation (1). Actually, high n-value is important for the realization of the motor performance [13]. That is, constant torque versus speed curve will be realized when the n-value of the $\mathrm{MgB}_{2}$ rotor bars are high enough.

In our motor, the $\mathrm{MgB}_{2}$ rotor bars are installed in the iron core, and then magnetic field dependency of the critical current is not serious problems. If the iron core suffers 
from the magnetic saturation, e.g., due to the overload, however, the $\mathrm{MgB}_{2}$ wires experience higher magnetic field. Then, we further measure the magnetic field dependencies of the current transport property as fundamental data. Figure 4 shows the measured data, and can be utilized for the overload characteristics of the fabricated motor.

\subsection{Fabrication of rotor bars}

One piece of the $\mathrm{MgB}_{2}$ wire is installed in a U-shaped oxygen-free copper bar for the support of such wire, as schematically shown in figure 5 (a). After installation, solder is packed in the ditch of the copper bars. Figure 5 (b) shows a photograph of the fabricated rotor bars. The same rotor bars are prepared at 44 in total.

\subsection{Fabrication of end rings}

Ring-shaped support made of oxygen-free copper is prepared, and then the $\mathrm{MgB}_{2}$ wires are wound 11 times as the end rings. After the completion of the windings, the wires are fixed by means of the solder. Figure 6 shows the photograph of the fabricated $\mathrm{MgB}_{2}$ end ring. Two end rings are fabricated for the short of the $\mathrm{MgB}_{2}$ rotor bars.

\subsection{Estimation of contact resistance}

The rotor bars and the end rings are connected by means of the solder in this study, and such contact resistance should be lower as small as possible. Then, the contact resistance of the soldered $\mathrm{MgB}_{2}$ rotor bars is estimated by the experiment.

Figure 7 shows the schematic diagram of the soldered $\mathrm{MgB}_{2}$ rotor bars. The overlapped lengths at $10 \mathrm{~mm}$ are soldered, and then the contact resistance is measured by means of the four-probe method. The obtained results are shown as a function of the temperature in figure 8. The critical current of $\mathrm{MgB}_{2}$ rotor bar is also plotted for the reference. As can be clearly seen, the contact surface resistance (resistivity $\mathrm{x}$ solder thickness, $\rho l_{\text {sol }}$ ) decreases to be about $2 \times 10^{-7} \Omega \mathrm{mm}^{2}$ when the wire transits to be the superconducting state. This value is adequate for the fabrication of the cage windings with low contact resistance.

\subsection{Integration of rotor bars and end rings}


The fabricated $\mathrm{MgB}_{2}$ rotor bars and end rings are integrated for the completion of the cage windings. Figure 9 shows the schematic diagram of the cage windings. The $\mathrm{MgB}_{2}$ surfaces of the rotor bars are soldered with that of the end rings. The soldering process is carefully carried out in order to realize the low contact resistance as explained in section 2.4.

Figure 10 shows a photograph of the completed $\mathrm{MgB}_{2}$ rotor. As can be seen, the $\mathrm{MgB}_{2}$ windings are mechanically supported by the coppers.

\section{Test set-up}

\subsection{Installation of $\mathrm{MgB}_{2}$ rotor in the stator}

The completed $\mathrm{MgB}_{2}$ rotor is installed in the conventional (copper) stator (3-phase, 4-pole, $200 \mathrm{~V}$ ). The photograph of the stator core (silicon steel, slot number: 36) is shown in figure 11 . The gap between the stator and the rotor is $0.5 \mathrm{~mm}$.

\subsection{Test set-up}

Although the test should be performed in $\mathrm{LH}_{2}$, LHe $(4 \mathrm{~K})$ is utilized as a first step in this study because of the safety reason. Figure 12 (a) illustrates the schematic diagram of the test system. The fabricated $\mathrm{MgB}_{2}$ motor is hanged from the top flange of the cryostat, by means of four pieces of the stainless bars in the metal cryostat. And then, the shaft of the motor is connected to the room temperature contactless torque transducer and the load by means of the magnetic seal.

Before the experiment, the lubrication oil of the bearings is removed by using acetone. The motor is excited with the commercial PWM (Pulse Width Modulation) inverter, and then the rotation speed as well as the torque is measured as increasing the load. Figure 13 shows the photograph of the experimental set-up for the load test.

\section{Results and Discussion}

\subsection{No-load test}

Figure 14 shows the no-load test results at $4 \mathrm{~K}$ and $60 \mathrm{~Hz}$. The $\mathrm{MgB}_{2}$ motor is firstly immersed in liquid helium ( $4 \mathrm{~K}$ ), and then the input line voltage is increased from zero at $60 \mathrm{~Hz}$. As the figure shows, the motor does not rotate when the line voltage is lower 
than $100 \mathrm{~V}$. This is because the $\mathrm{MgB}_{2}$ rotor windings shield the magnetic fluxes supplied from the stator windings [5]. And, the corresponding primary current increases almost linearly at this voltage region. Further increment of the voltage, on the other hand, makes the zero resistance windings transit the flux-flow (dissipative) state. And then, the rotor starts rotating with slip mode. Finally, the induced electric field of the cage windings decreases to zero again as accelerating the rotor, and then the interlinked magnetic fluxes trapped in the windings. At this state, the rotor is pulled in to be the synchronous rotation (1800 rpm). It should be noted that the above-mentioned process realizes automatically owing to the intrinsic nature of the superconducting induction motor. After the synchronism, the primary current decreases, i.e., $V_{1}>130 \mathrm{~V}$. Such no-load characteristic is qualitatively the same with those of the already reported motor that introduce the oxide High temperature Superconductor (HTS) wires, i.e., BSCCO or YBCO [7, 8].

Here, so-called minimum starting voltage [5] $V_{\text {min }}$, at which the motor start rotating, can be derived from the nonlinear electrical equivalent circuit as follows.

$$
V_{\min }=\sqrt{r_{1}^{2}+\omega^{2}\left(l_{1}+l_{2}^{\prime}\right)^{2}} I_{\mathrm{c}},
$$

where, $r_{1}(=1.2 \mathrm{~m} \Omega)$ denotes the primary resistance, and $\omega(=2 \pi f)$ the angular frequency. $l_{1}$ and $l_{2}$ ' mean, respectively, the leakage inductance at primary and secondary sides. The quantity with prime at the right shoulder denotes that such value is converted to the primary side. Then, primary converted critical current $I_{\mathrm{c}}{ }^{\prime}\left(=I_{\mathrm{C}} / N ; N\right.$ : effective turn number of the stator windings) is 20.0 A@4 K (= 535 A/26.7). By using the measured value of $\omega\left(l_{1}+l_{2}{ }^{\prime}\right)=3.7 \Omega @ 60 \mathrm{~Hz}, V_{\min }$ is estimated to $128.5 \mathrm{~V}$, and this value agree with the pull-in voltage of $130 \mathrm{~V}$ (figure 14).

\subsection{Load test}

Next, the load tests are carried out in liquid helium. The motor is firstly pulled in to be the synchronous speed at no-load condition. And then, the torque, the primary information (voltage, current, phase, power), the temperature of the motor and the rotation speed are measured as applying the load by use of the prony-brake. In this study, the ratio of the input voltage and the primary frequency is always controlled to be 200 V/60 Hz. Figure 15 shows the typical load test results. It should be noted that the data at $5 \mathrm{~Hz}$ and $10 \mathrm{~Hz}$ are only discussed in this study. This is because further increment of the driving frequency results in the temperature rise of the motor in liquid helium.

It can be clearly seen in figure 15 (a), the motor possesses the maximum 
synchronous torque about $38 \mathrm{Nm}$. Furthermore, almost constant slip torque is realized by applying the overload, and then the motor shows static torques at $38 \mathrm{Nm}$ for $5 \mathrm{~Hz}$ and $40 \mathrm{Nm}$ for $10 \mathrm{~Hz}$, respectively. That is, stable rotation is possible for wide speed range from 0 to synchronous speed. Actually, the characteristic of the constant torque versus slip curve comes from the steep take-off of the current transport property of $\mathrm{MgB}_{2}$ cage windings [13], and this is one of the merits of the $\mathrm{MgB}_{2}$ motor. It should be noted that the temperature of the stator (copper) windings remains to be the constant value during the tests, as shown in figure (a).

Figure 15 (b) shows the corresponding efficiency characteristics. We can realize the maximum efficiency at about $92 \%$. In the present motor, unfortunately, the commercial bearings are utilized in liquid helium without lubrication oil, and the mechanical losses in such motor will enlarge. Therefore, the total motor efficiency will further increase when we can reduce such losses.

\section{Conclusion}

In this study, we fabricated the induction motor that introduces the superconducting $\mathrm{MgB}_{2}$ rotor windings. Mono-core $\mathrm{MgB}_{2}$ wires are produced by use of the in-situ method, and the cage windings were fabricated with the contact surface resistance of the order of $10^{7} \Omega \mathrm{mm}^{2}$. The fabricated motor was tested in liquid helium. It was shown that the fabricated motor successfully pulled in to be the synchronous rotation. Further, the synchronous torque and the almost constant torque versus speed curve were obtained. In near future, we will carry out the liquid hydrogen circulation test.

\section{Acknowledgements}

This work was supported by the Industrial Technology Research Grant Program in 2008 (08B38006a) from the New Energy and Industrial Technology Development Organization (NEDO) of Japan.

\section{References}

[1] K. Kajikawa and T. Nakamura, IEEE Trans. Appl. Supercond., 19, 3, (2009) 1669-1673

[2] D. Dew-Hughes, et al., UK Patent Application No. 9810361.7, 14th May 1998 
[3] L K Kovalev, et al., Supercond. Sci. Technol., 17(2003) S460

[4] M. Komori, et al., IEEE Trans. Appl. Supercond., 14, 2 (2004) 1659-1662

[5] T. Nakamura, Y. Ogama and H. Miyake, IEEE Trans. Appl. Supercond., 17, 2 (2007) 1615-1618

[6] T. Nakamura, Y. Ogama, H. Miyake, K. Nagao and T. Nishimura, Supercond. Sci. Technol., 20 (2007) 911-918

[7] K. Nagao, T. Nakamura, T. Nishimura, Y. Ogama, N. Kashima, S. Nagaya, K. Suzuki, T. Izumi and Y. Shiohara, Supercond. Sci. Technol., vol. 21 (2008) 015022(5pp) [8] T. Nakamura, K. Nagao, T. Nishimura, Y. Ogama, M. Kawamoto, T. Okazaki, N. Ayai and H. Oyama, Supercond. Sci. Technol., 21, 8 (2008) 085006(5pp)

[9] T. Nakamura, T. Nishimura, K. Nagao, K. Matsumura and Y. Ogama, Proc. XVIII International Conference on Electrical Machines (ICEM'08), September 6-9, 2008, Vilamoura, Portugal, ID. 1278 (5pp)

[10] K. Kajikawa, T. Kawano, R. Osaka, T. Nakamura, M. Sugano, M. Takahashi and T. Wakuda, Supercond. Sci. Technol., 23, 4 (2009) 045026

[11] K. Kajikawa, R. Osaka, T. Nakamura, M. Sulgano and T. Wakuda, Journal of Superconductivity and Novel Magnetism, 24, 1-2 (2011) 987-991

[12] E.J. Kramer, Journal of Applied Physics, 44 (1973) 1360

[13] T. Konishi, T. Nakamura, T. Nishimura and N. Amemiya, IEEE Transactions on Applied Superconductivity, 21, 3 (2011) 1123-1126 


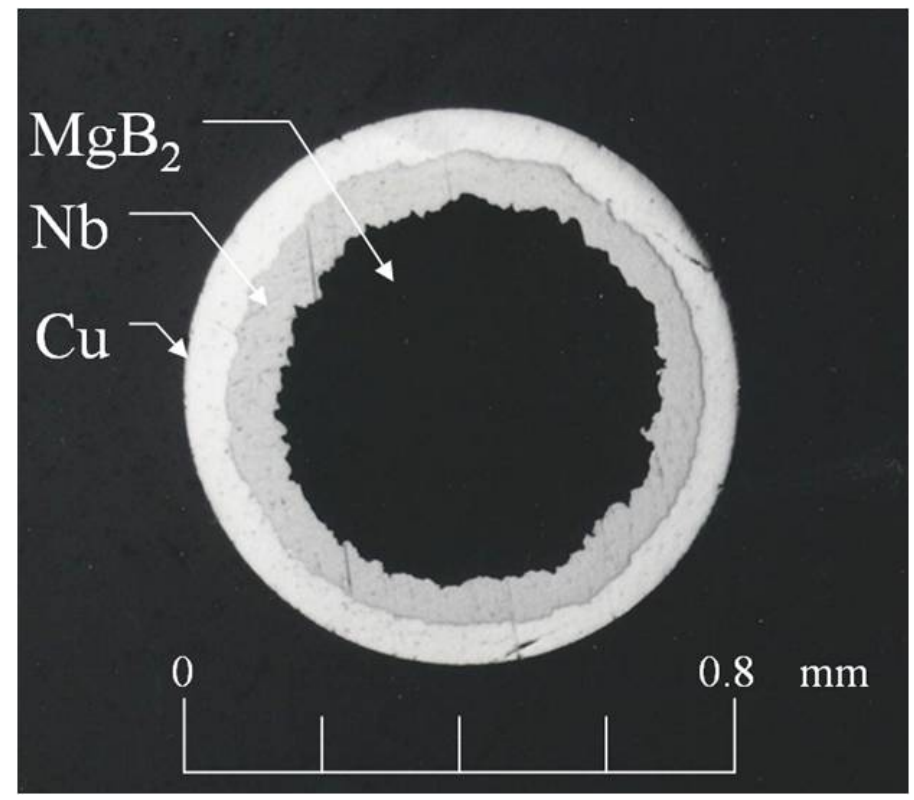

Figure 1 Optical micrograph of cross section of $\mathrm{MgB}_{2}$ mono-core round wire [10]

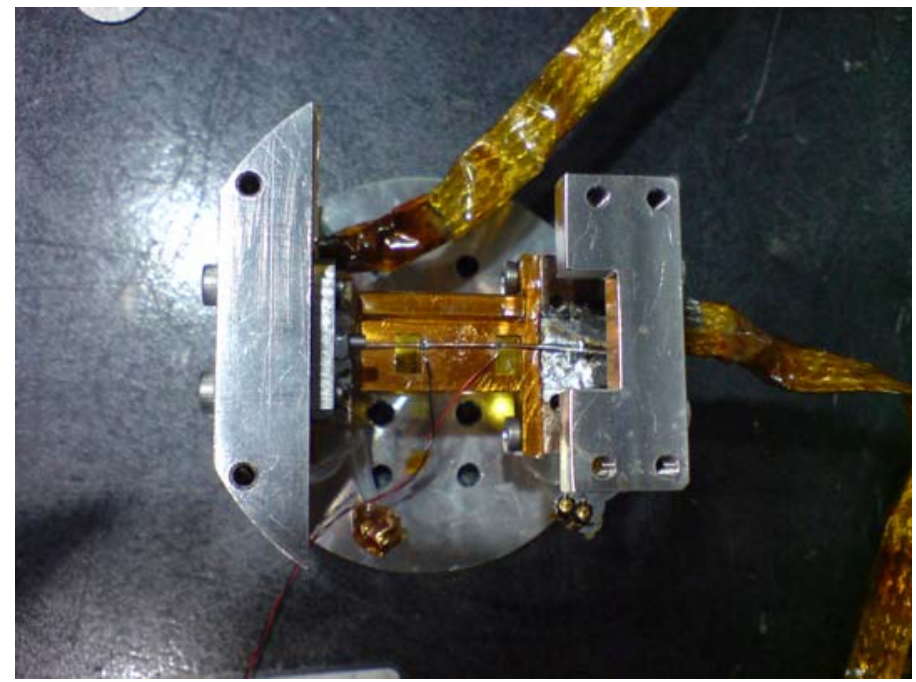

Figure 2 Photograph of $\mathrm{MgB}_{2}$ sample on the holder (Copper stage). The distance between the potential taps is $11 \mathrm{~mm}$. 


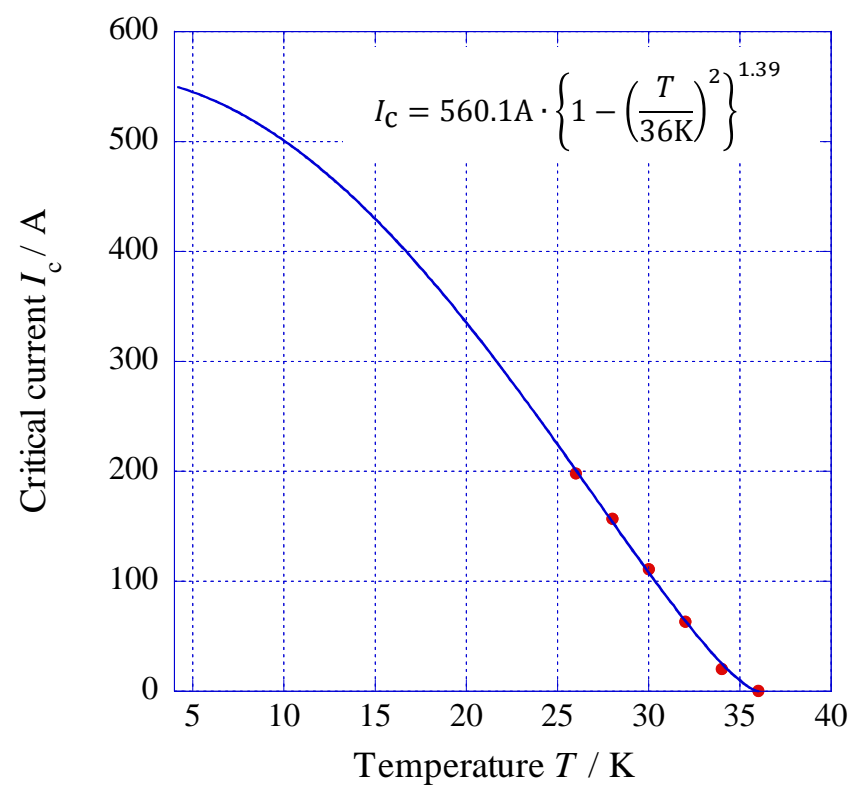

(a) Critical current $\left(I_{c}\right)$

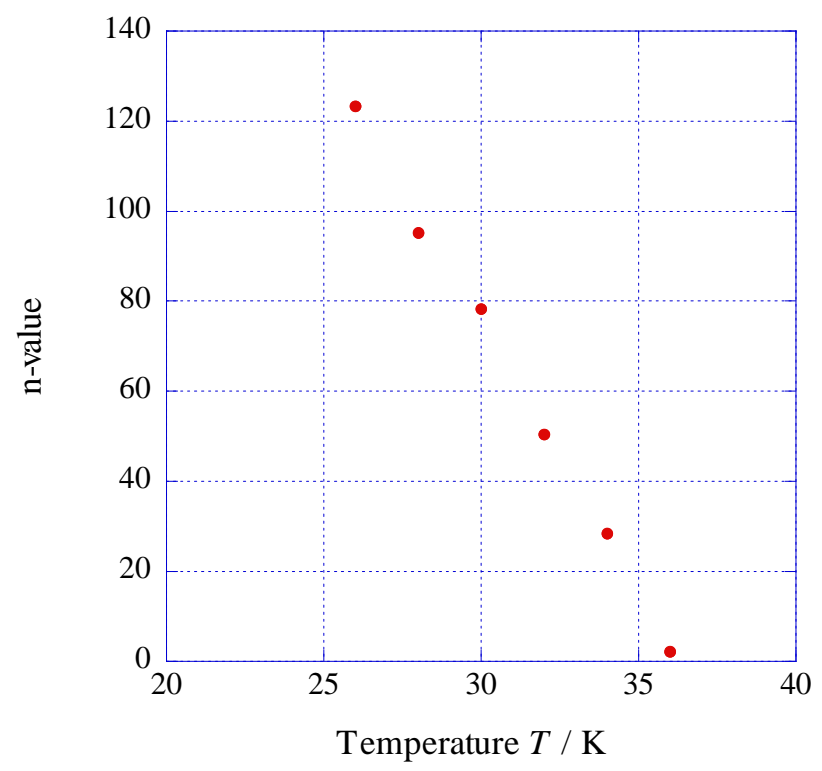

(b) n-value

Figure 3 Temperature dependence of current transport property of $\mathrm{MgB}_{2}$ wire (symbols: experimental results, curve in figure (a): Kramer’s expression (equation (1)) 


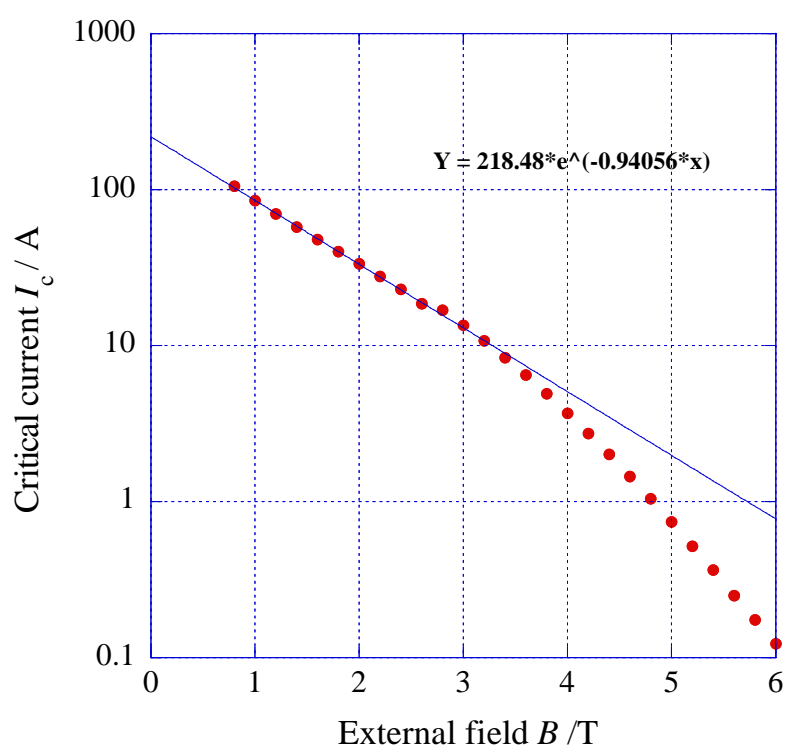

(a) Critical current $\left(I_{\mathrm{c}}\right)$

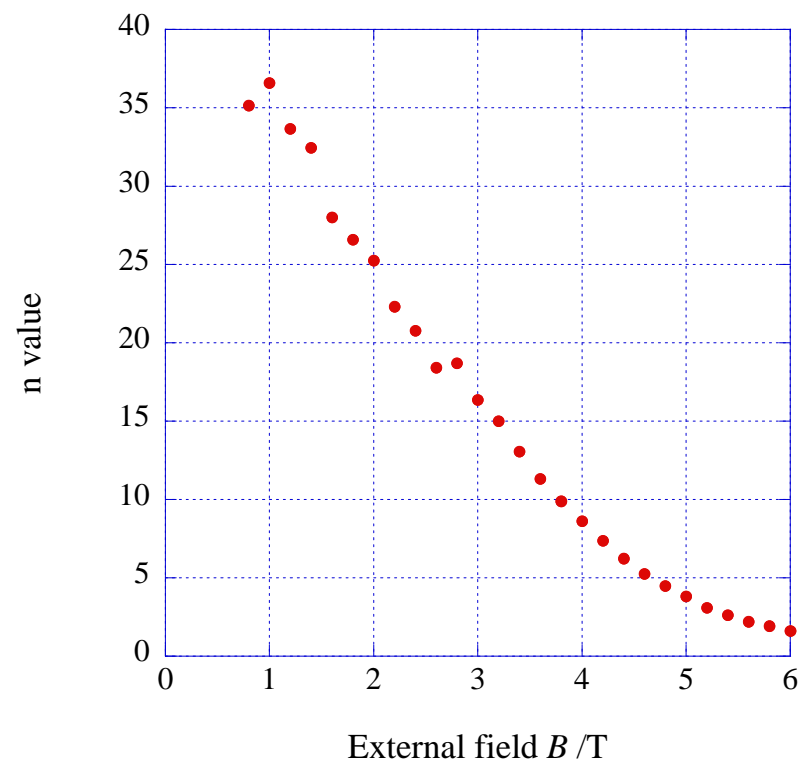

(b) n-value

Figure 4 Magnetic field dependence of current transport property of $\mathrm{MgB}_{2}$ wire at $20 \mathrm{~K}$ 


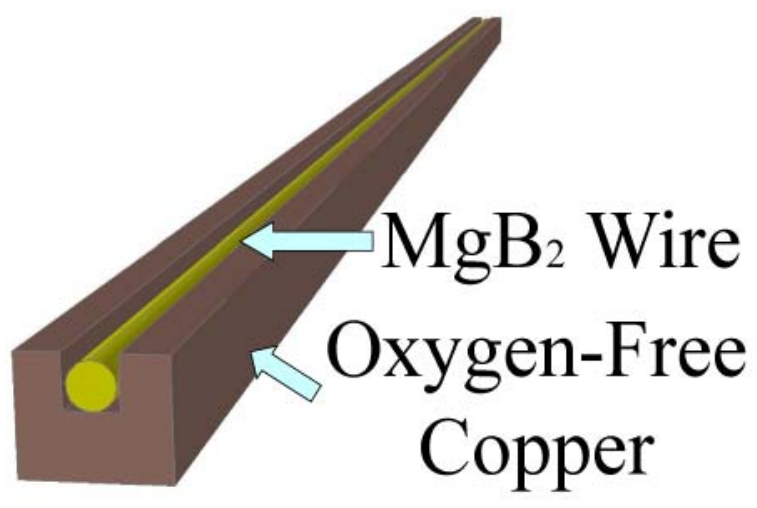

(a) Schematic diagram

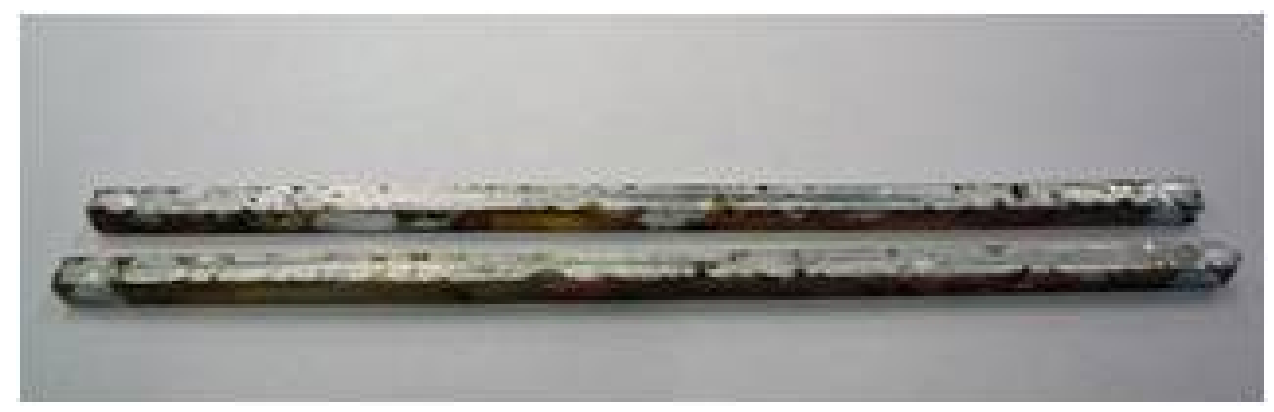

(b) Photograph

Figure 5 Fabricated $\mathrm{MgB}_{2}$ rotor bars 


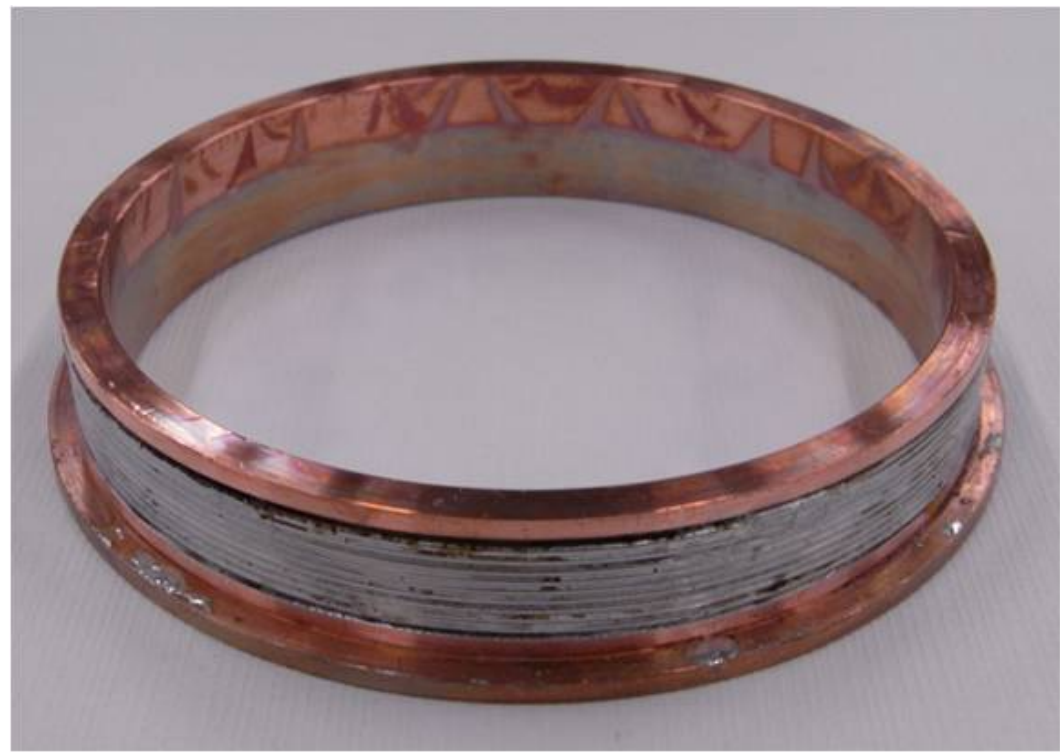

Figure 6 Fabricated $\mathrm{MgB}_{2}$ end ring

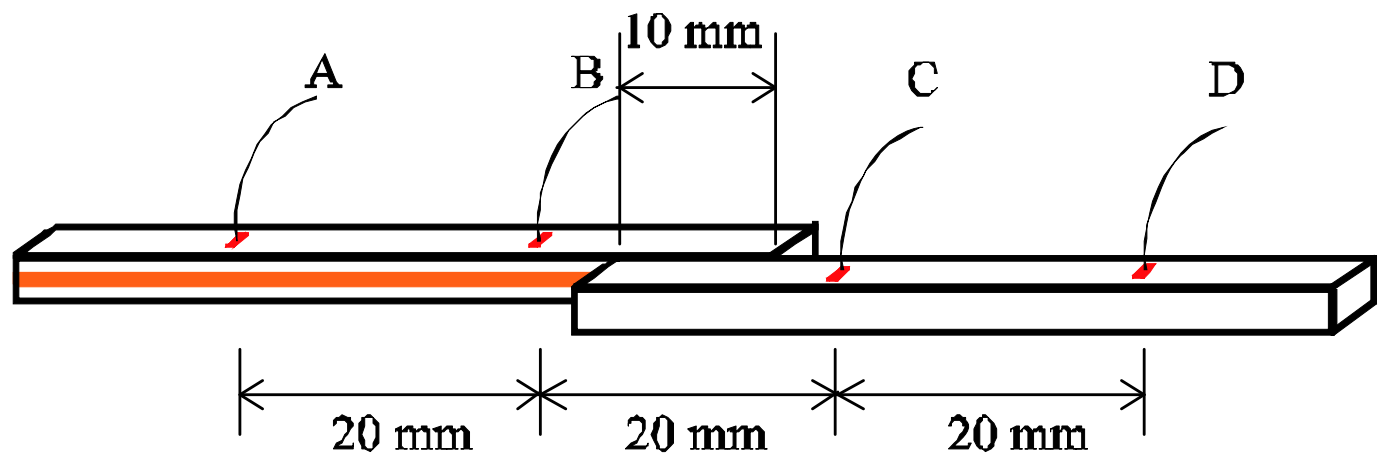

Figure 7 Schematic diagram of soldered $\mathrm{MgB}_{2}$ rotor bar 


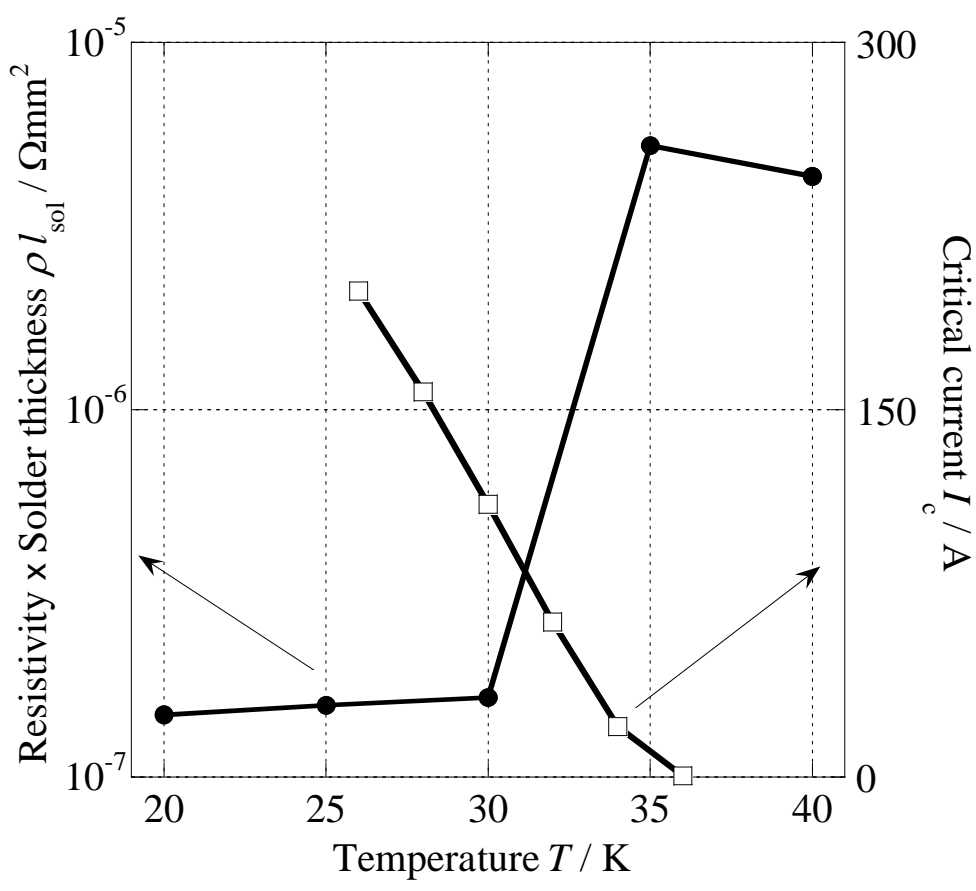

Figure 8 Experimental results of resistivity x solder thickness, $\rho l_{\text {sol }}$, of soldered $\mathrm{MgB}_{2}$ rotor bar (figure 7). Critical current of the $\mathrm{MgB}_{2}$ wire is also plotted for the reference.

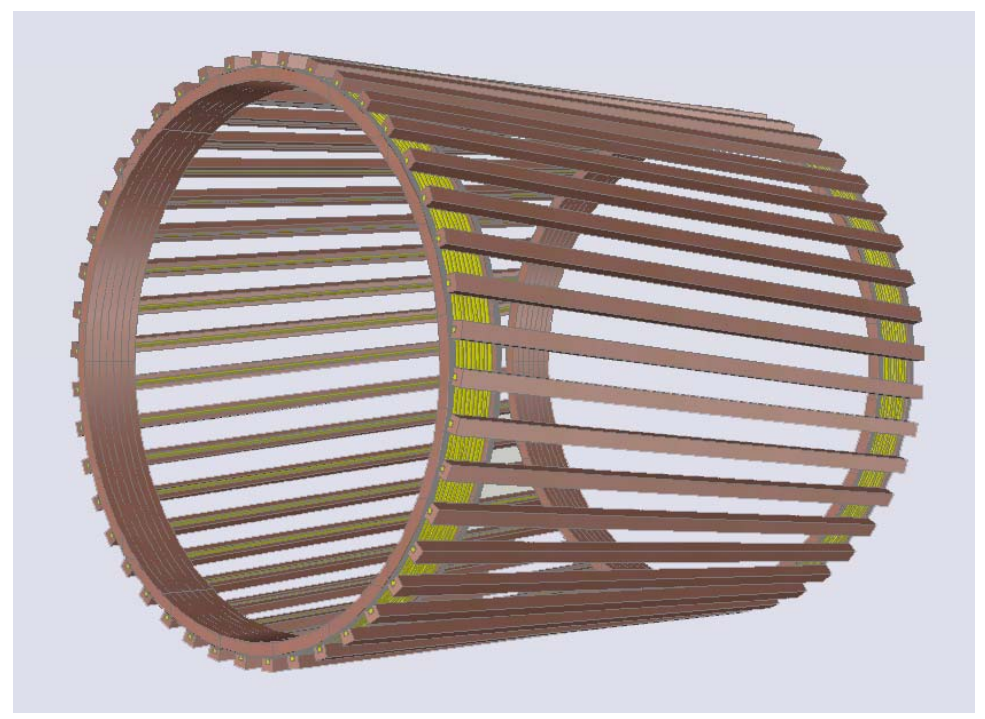

Figure 9 Schematic diagram of $\mathrm{MgB}_{2}$ cage windings 


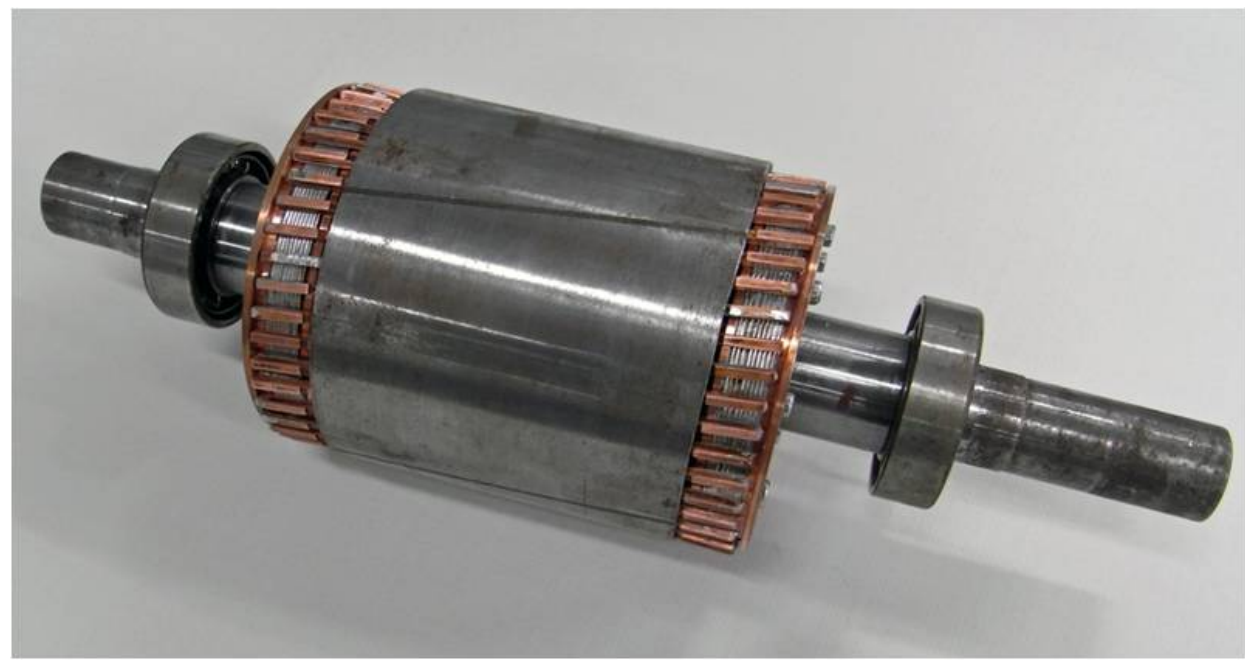

Figure 10 Photograph of the integrated $\mathrm{MgB}_{2}$ rotor

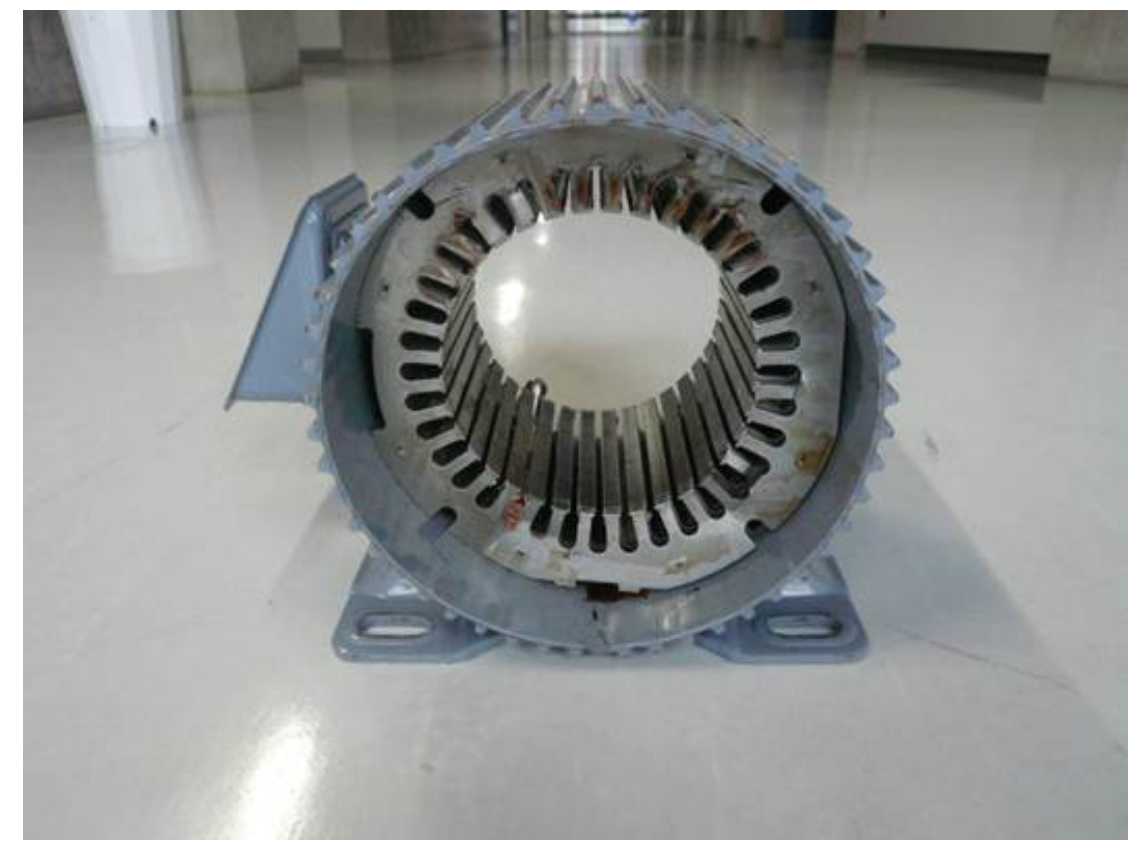

Figure 11 Photograph of stator core (slot number: 36) 


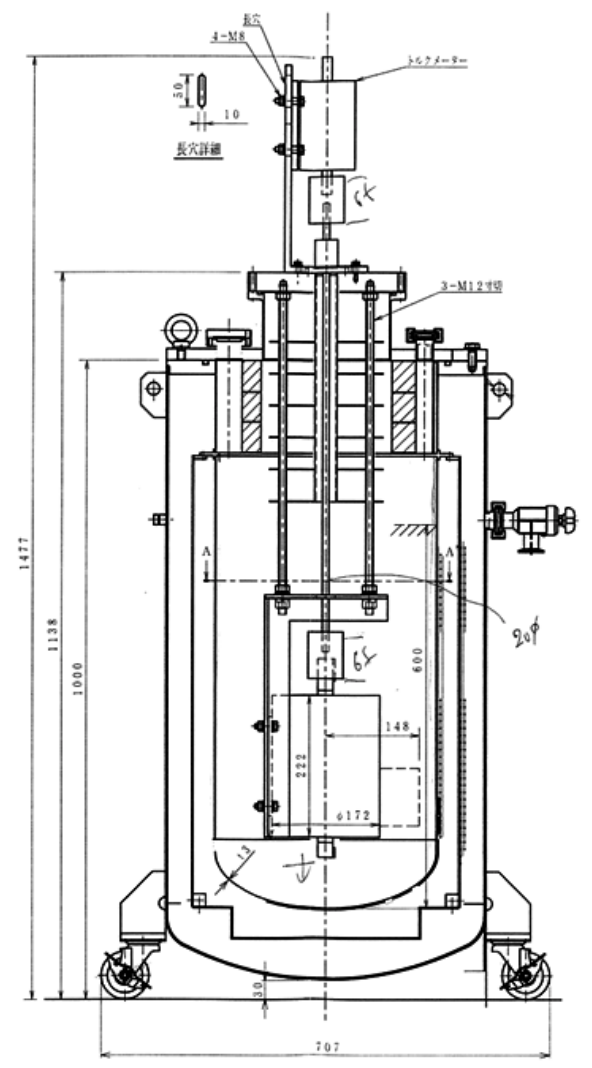

(a) Schematic diagram

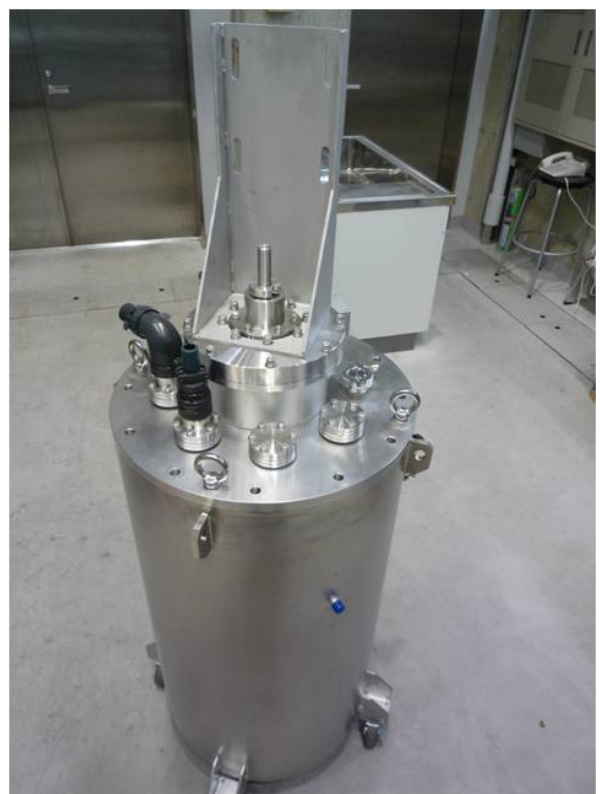

(b) Photograph

Figure 12 Test cryostat 


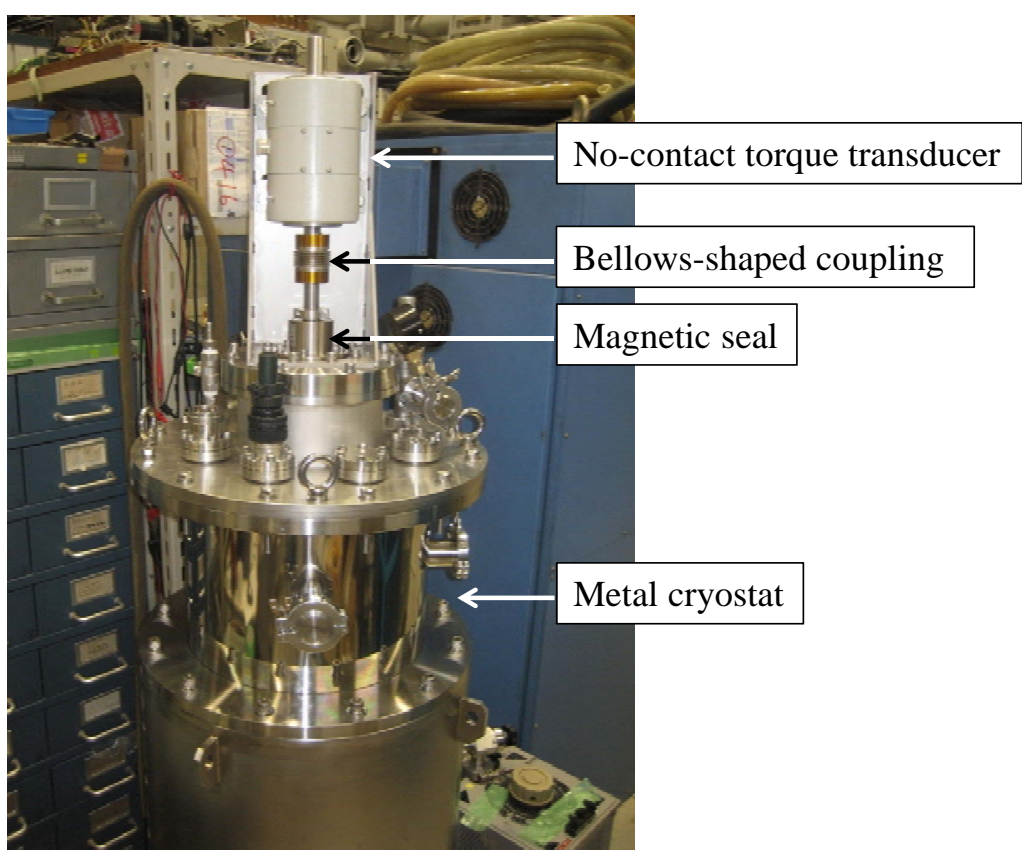

Figure 13 Experimental set-up for load test

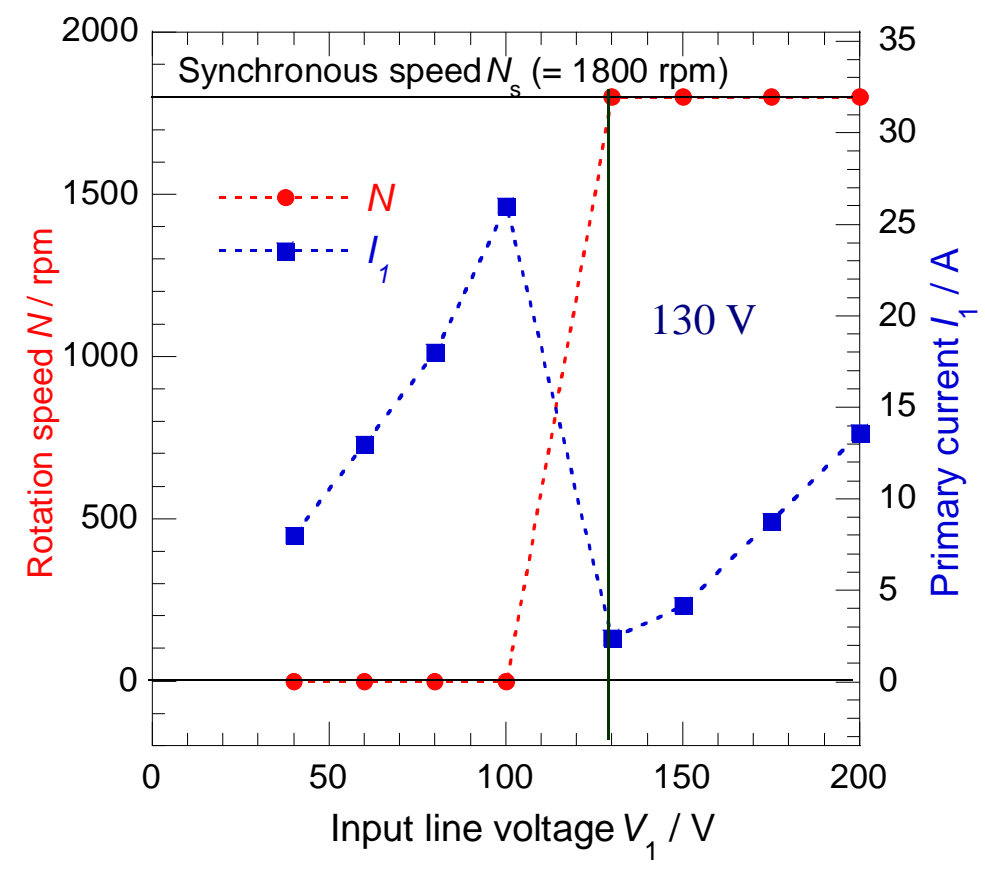

Figure 14 No-load test result at $4 \mathrm{~K}$ and $60 \mathrm{~Hz}$ 


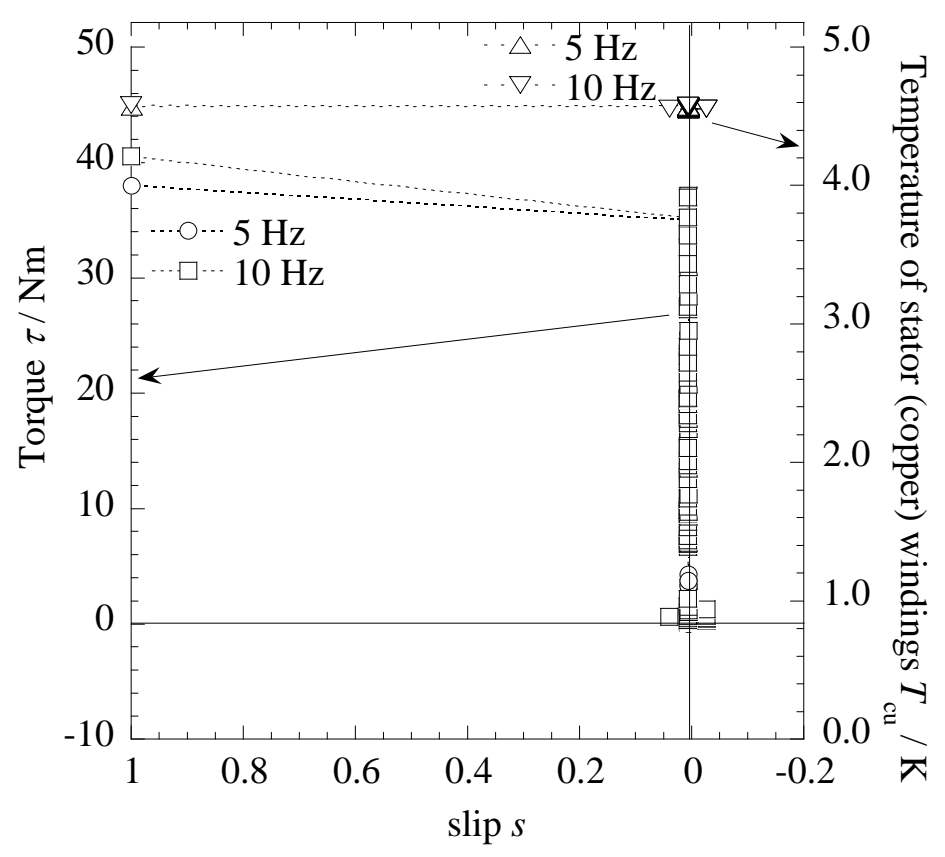

(a) Torque and temperature of stator (copper) windings

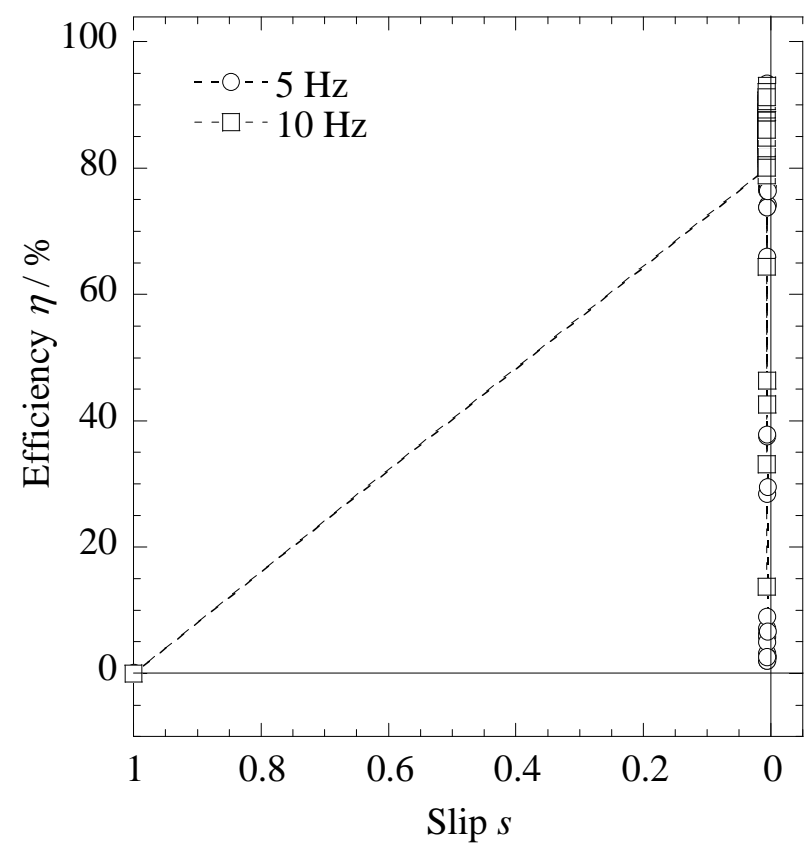

(b) Efficiency

Figure 15 Load test results (slip, $s$, is defined as $s=\left(N_{\mathrm{s}}-N\right) / N_{\mathrm{s}} ; N_{\mathrm{s}}$ : synchronous speed, $N$ : Actual speed) 